\title{
The effect of MLS laser radiation on cell lipid membrane
}

\author{
Kamila Pasternak-Mnich', Dominika Wróbel2 ${ }^{2}$, Olga Nowacka², Ireneusz Pieszyński", \\ Maria Bryszewska², Jolanta Kujawa' \\ ${ }^{1}$ Department of Medical Rehabilitation, Faculty of Military Medicine, Medical University of Lodz, Poland \\ 2 Department of General Biophysics, Faculty of Biology and Environmental Protection, University of Lodz, Poland
}

Pasternak-Mnich K, Wróbel D, Nowacka O, Pieszyński I, Bryszewska M, Kujawa J. The effect of MLS laser radiation on cell lipid membrane. Ann Agric Environ Med. 2018; 25(1): 108-113. doi: 10.5604/12321966.1230734

\section{Abstract surface energy density was within the range $0.46-4.9 \mathrm{~J} / \mathrm{cm}^{2}$. radiation used. \\ Key words \\ liposomes, laser irradiation, laser therapy, MLS M1 system}

Introduction. Authors of numerous publications have proved the therapeutic effect of laser irradiation on biological material, but the mechanisms at cellular and subcellular level are not yet well understood.

Objective. The aim of this study was to assess the effect of laser radiation emitted by the MLS M1 system (Multiwave Locked System) at two wavelengths ( $808 \mathrm{~nm}$ continuous and $905 \mathrm{~nm}$ pulsed) on the stability and fluidity of liposomes with a lipid composition similar to that of human erythrocyte membrane or made of phosphatidylocholine.

Materials and method. Liposomes were exposed to low-energy laser radiation at surface densities $195 \mathrm{~mW} / \mathrm{cm}^{2}$ (frequency $1,000 \mathrm{~Hz}$ ) and $230 \mathrm{~mW} / \mathrm{cm}^{2}$ (frequency $2,000 \mathrm{~Hz}$ ). Different doses of radiation energy in the range 0-15 J were applied. The

Results. The fluidity and stability of liposomes subjected to such irradiation changed depending on the parameters of

Conclusions. Since MLS M1 laser radiation, depending on the parameters used, affects fluidity and stability of liposomes with the lipid content similar to erythrocyte membrane, it may also cause structural and functional changes in cell membranes.

\section{INTRODUCTION}

Despite years of controversy about the efficacy of low level laser therapy (LLLT), it is becoming increasingly well-established as a physical therapy method. Numerous publications describe the analgesic, anti-inflammatory and biomodulating effects of laser radiation [1]. The effects of the biostimulating action include changes of cell metabolism, such as increased ATP synthesis, increased synthesis of proteins, DNA and RNA, acceleration of cell division, increased enzyme activity, increased number of mitochondria and enhanced membrane potential. A significant effect of stimulation includes increases in the activity and number of T lymphocytes, which influence regeneration processes by releasing growth factors locally [2-7]. In classical low-energy laser therapy, a specific laser radiation wavelength is applied continuously or in pulses. At the beginning of the 21st century the potential concurrent application of synchronised dual wavelengths - Multiwave Locked System (MLS) and HILT high-energy radiation - was proposed $[8,9]$. MLS allows two different wavelengths to be applied simultaneously: $\lambda_{1}=808 \mathrm{~nm}$ in continuous emission and $\lambda_{2}=905 \mathrm{~nm}$ in pulsed emission. MLS provides laser therapy from two sources and, regardless of the operation of the laser diode (continuous or pulse), the energy dose is applied simultaneously, enabling the energy from both sources of laser radiation to be distributed uniformly over the irradiated surface. However, available studies do not provide sufficient evidence to confirm whether MLS has higher therapeutic value than traditional laser therapy.

Address for correspondence: Kamila Pasternak-Mnich, Department of Medical Rehabilitation, Faculty of Military Medicine, Medical University of Lodz, Poland E-mail: kamila.pasternak@umed.lodz.pl

Received: 12 November 2013; accepted: 25 March 2013; first published on January 2017

\section{OBJECTIVE}

The aim of this study was to evaluate the effect of MLS laser irradiation on cell membrane structure and function by assessing its effect on the fluidity and stability of liposomes.

\section{MATERIALS AND METHODS}

The liposomes were composed of phosphatidylcholine (PC) or had a lipid composition similar to that of erythrocyte membranes: cholesterol $(\mathrm{CH})$, phosphatidylcholine (PC), sphingomyelin (SM), phosphatidylethanolamine (PE), phosphatidylserine (PS). They were irradiated using the MLS M1 system $\left(\lambda_{1}=\right.$ continuous emission at $808 \mathrm{~nm}$ and $\lambda_{2}=$ pulsed emission at $905 \mathrm{~nm}$ ) with surface energy density $0.46-4.9 \mathrm{~J} / \mathrm{cm}^{2}$. Power densities at the emission of the pulse wave at $1,000 \mathrm{~Hz}$ or $2,000 \mathrm{~Hz}$ were 195 and $230 \mathrm{~mW} / \mathrm{cm}^{2}$, respectively. The doses of laser energy were $0,1.5,3,6,9$, 12 and $15 \mathrm{~J}$.

Changes in liposome fluidity under the influence of laser irradiation determined using fluorescence spectroscopy. In order to obtain $1 \mathrm{ml}$ of liposomes, $189 \mu \mathrm{l}$ of $20 \mathrm{mg} / \mathrm{ml}$ lipid solution (PC) in chloroform was used. Ten microlitres of a $1 \mathrm{mM}$ solution of a fluorescent label (TMA - DPH in methanol or DPH in THF) was added and the mixture placed in an evaporator (KNF Neuberger Laboport, USA). In order to obtain a uniform film of lipids on the bottom of the flask, it was continuously rotated. The film was dried at $25^{\circ} \mathrm{C}$ for 90 minutes. One millilitre of PBS was then added to the flask and incubated in a water bath at $40^{\circ} \mathrm{C}$ for 15 minutes to obtain a uniform suspension of lipids in buffer. This suspension was extruded (Extruder Avanti Polar Lipids, USA). A forming 
membrane with $100 \mathrm{~nm}$ pores was used. A $2 \mathrm{ml}$ aliquot of the liposome suspension in PBS (concentration $2.1 \mathrm{mg} / \mathrm{ml}$ ) was irradiated. For each sample, fluorescence anisotropy was determined immediately before and immediately after the irradiation using a Perkin-Elmer LS-50B spectrofluorimeter (United Kingdom). The excitation wavelength was $348 \mathrm{~nm}$ and the emission wavelength $426 \mathrm{~nm}$; the slit widths for excitation and emission were both $7.0 \mathrm{~nm}, \mathrm{GF}=1.48$. Six repetitions were performed.

Membrane fluidity was also determined in liposomes with lipid compositions similar to that of human erythrocyte membranes. In order to prepare $1 \mathrm{ml}$ of these liposomes, the following solutions of lipids $(4.2 \mathrm{mg} / \mathrm{ml})$ in chloroform were used: $51.8 \mu \mathrm{l} \mathrm{CH}, 38.3 \mu \mathrm{l} \mathrm{PC}, 64.1 \mu \mathrm{l} \mathrm{SM}, 12.4 \mu \mathrm{l} \mathrm{PE}, 2 \mu \mathrm{l} \mathrm{PS}$ (at the same concentration as the PC), and $5 \mu$ l of $1 \mathrm{mM}$ label (TMA-DPH or DPH).

Fluorescence anisotropy was determined using two labels: TMA-DPH and DPH. TMA-DPH attaches to the outer monolayer of the liposome membrane, while DPH attaches to the inner monolayer. The fluorescence anisotropy coefficients (r) were calculated from Jablonski's equation:

$$
r=\frac{I v v-G I v h}{I v v+2 G I v h}
$$

where $I_{v v}, I_{v h}$ are the vertical and horizontal fluorescence intensities, respectively, to the vertical polarization of the excitation light beam. The factor $G=I_{h \nu} / I_{h h}$ (grating correction factor) corrects the polarizing effects of the monochromator. The location of fluorescent labels in specific regions of the liposome membrane allows evaluation of both the changes in fluidity and the layer in which these changes occur. An increase in fluorescence anisotropy means a decrease in membrane fluidity.

Changes in liposome fluidity under the influence of laser irradiation determined using fluorescence spectroscopy. In order to obtain $1 \mathrm{ml}$ of liposomes, $378 \mu \mathrm{l}$ of $20 \mathrm{mg} / \mathrm{ml}$ lipid solution (PC) in chloroform was used. One millilitre of carboxyfluorescein solution $(125 \mathrm{mg} / \mathrm{ml})$ in a basic medium was added, and $\mathrm{pH}$ then adjusted to 7.4. The sample was incubated at $40^{\circ} \mathrm{C}$ with stirring. This solution was extruded (Extruder Avanti Polar Lipids, USA). A forming membrane with $100 \mathrm{~nm}$ pores was used. The liposomes were purified by passage through a Sephadex G-75 column (height $60 \mathrm{~mm}$, diameter $14 \mathrm{~mm}$ ). A $4.2 \mathrm{mg} / \mathrm{ml}$ liposome suspension in PBS was irradiated. The fluorescence intensity of each sample before and after irradiation was determined using a PerkinElmer LS-50B spectrofluorimeter (United Kingdom). The excitation wavelength was $492 \mathrm{~nm}$ and the emission wavelength $532 \mathrm{~nm}$; the slit widths were $2.5, \mathrm{GF}=1.00$. Six replicates were measured.

Statistical analysis. The six values obtained for each sample were presented as mean \pm SE. The distribution was consistent with normality according to a Shapiro-Wilk test. One-way ANOVA was used for statistical analysis. Fisher's LSD test and Student's t test were performed to determine the statistical significance of differences between multiple samples and two samples, respectively. Significance level $\alpha=0.05$. Statgraphics Centurion XVI ver.16.1.18 was used for calculations.

\section{RESULTS}

The fluorescence anisotropy coefficients (r) of the labels were used to evaluate the effect of a dose of laser radiation energy from the MLS M1 with pulsed emission frequencies of $1,000 \mathrm{~Hz}$ or $2,000 \mathrm{~Hz}$ on the fluidities of the external and internal monolayers of phosphatidylcholine liposomes with lipid composition similar to erythrocyte membranes. Samples subjected to MLS laser radiation were compared to non-irradiated membranes.

Influence of MLS laser radiation on membrane fluidity in phosphatidylcholine liposomes. Low-energy laser radiation at $1,000 \mathrm{~Hz}$, with doses ranging from $1.5 \mathrm{~J}-15 \mathrm{~J}$, significantly influenced the fluorescence anisotropy coefficients ( $r$ ) of the DPH label $(\mathrm{p}<0.001)$. The fluidity of the inner monolayer of the liposomes was lower than in the non-irradiated sample, irrespective of the applied energy dose. There was no significant difference in fluidity in the inner monolayers of PC liposomes between the corresponding energy doses ( $>0.05$ ) (Fig. 1). The relative changes in average fluidity of the liposome inner monolayers for the same doses of energy at different frequencies lay in the range $14.8 \%-18.3 \%$. The biggest change of relative fluidity was observed for the lowest dose of radiation energy.

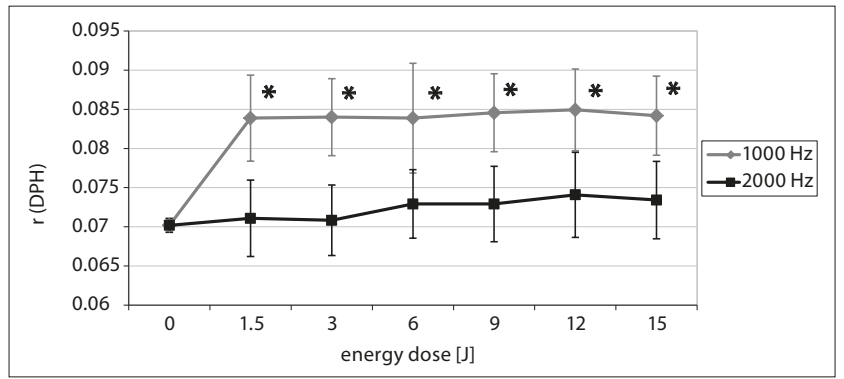

Figure 1. Fluorescence anisotropy coefficient ( $r$ ) for DPH fluorescent label in bilayers of phosphatidylcholine liposomes versus dose of MLS laser radiation with frequency of $1,000 \mathrm{~Hz}$ and $2,000 \mathrm{~Hz}$.

* statistically significant difference, compared to a dose of $0 \mathrm{~J}$.

The fluidity of the outer monolayers of the phosphatidylcholine liposomes was significantly changed by laser radiation at both $\mathrm{f}=1,000 \mathrm{~Hz}(\mathrm{p}<0.01)$ and $\mathrm{f}=2,000 \mathrm{~Hz}$ $(\mathrm{p}<0.001)$ (Fig. 2). The fluidity of the monolayer was greater than in the non-irradiated sample for energy doses of $6 \mathrm{~J}$ and 9J at $\mathrm{f}=1000 \mathrm{~Hz}$, while at $\mathrm{f}=2,000 \mathrm{~Hz}$ this difference in fluidity

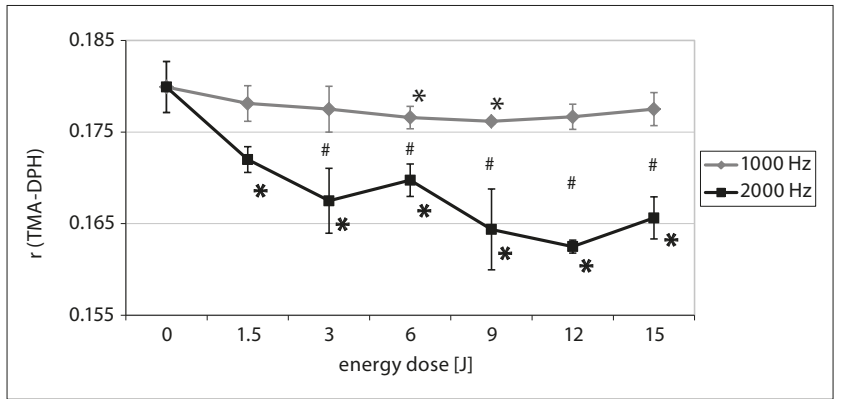

Figure 2. Fluorescence anisotropy coefficient ( $r$ ) for TMA-DPH fluorescent label in bilayers of phosphatidylcholine liposomes versus dose of MLS laser radiation with frequency of $1,000 \mathrm{~Hz}$ and $2,000 \mathrm{~Hz}$.

* statistically significant difference, compared to a dose of $0 \mathrm{~J}^{\prime}$

\# statistically significant difference between compared frequencies with the same energy dose. 
was observed at all energy doses. The liposome outer layers differed significantly in fluidity for corresponding doses of radiation energy ranging from $3 \mathrm{~J}-15 \mathrm{~J}(\mathrm{p}<0.01)$. For an energy dose of $1.5 \mathrm{~J}$, the calculated $\mathrm{p}=0.0692$ revealed a tendency towards variation in monolayer fluidity.

Effect of laser radiation on membrane fluidity in liposomes with lipid composition similar to that of erythrocyte membranes. In the bilayers of liposomes with lipid composition similar to erythrocyte membranes, MLS laser energy doses caused changes in the fluorescence anisotropy coefficient ( $r$ ) for DPH label at both frequencies, $1,000 \mathrm{~Hz}$ $(\mathrm{p}<0.001)$ and $2,000 \mathrm{~Hz}(\mathrm{p}<0.01)$ (Fig. 3). In the case of 1,000 , the effect on inner monolayer fluidity in the irradiated liposomes was lower than in the control sample for each dose of energy; at 2,000 Hz, this effect was apparent only for the $1.5 \mathrm{~J}$ energy dose. For the other energy doses, the changes in fluidity were not significantly different from those in a nonirradiated sample. The fluidities of the inner layers differed significantly at both frequencies only for $6 \mathrm{~J}$ and $12 \mathrm{~J}(\mathrm{p}<0.05)$.

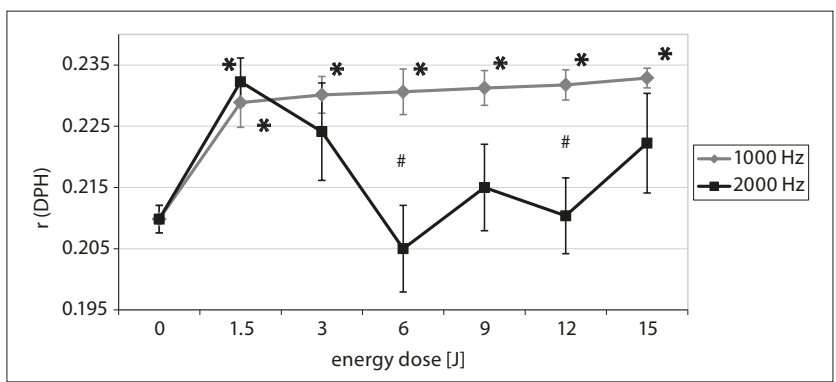

Figure 3. Fluorescence anisotropy coefficient ( $r$ ) for DPH fluorescent label in bilayers of liposomes with lipid composition similar to erythrocyte membranes versus dose of MLS laser radiation with frequency of $1,000 \mathrm{~Hz}$ and $2,000 \mathrm{~Hz}$.

* statistically significant difference, compared to a dose of $0 \mathrm{~J}$.

\# statistically significant difference between compared frequencies with the same energy dose.

After MLS irradiation at $\mathrm{f}=1,000 \mathrm{~Hz}$, there was no significant difference in the outer layer fluidity of liposomes with composition similar to human red blood cell membrane between irradiated and non-irradiated samples over the whole range of energy doses ( $\mathrm{p}>0.05)$. However, at $\mathrm{f}=2,000 \mathrm{~Hz}$, the applied energy affected the change in fluidity in these outer monolayers $(\mathrm{p}<0.01)$. At energy doses of 1.5 and $3 \mathrm{~J}$, the fluidity was less than that in the control sample, and at these energy doses there were statistically significant differences between the two frequencies $(\mathrm{p}<0.01)$ (Fig. 4).

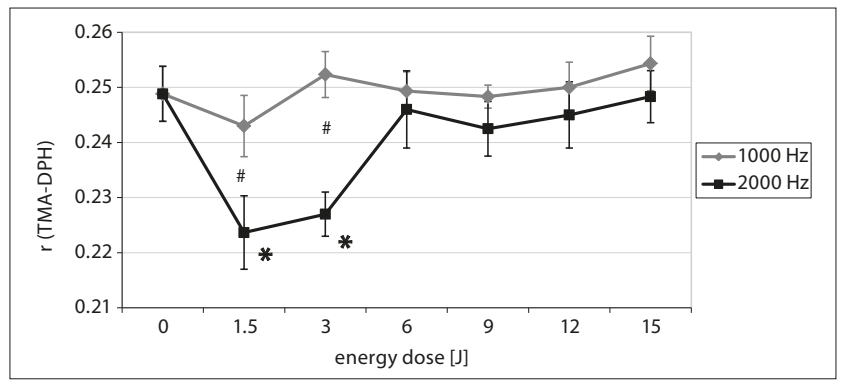

Figure 4. Fluorescence anisotropy coefficient ( $r$ ) for TMA-DPH fluorescent label in bilayers of liposomes with lipid composition similar to erythrocyte membranes versus dose of MLS laser radiation with frequency of $1,000 \mathrm{~Hz}$ and $2,000 \mathrm{~Hz}$. * statistically significant difference as compared to a dose of $0 \mathrm{~J}$

\# statistically significant difference between the compared frequencies at the same dose of energy.
Influence of MLS laser radiation on stability of phosphatidylcholine liposomes. The influence of MLS laser radiation on liposome stability differed between the two frequencies used $(\mathrm{p}<0.001)$. At $\mathrm{f}=1,000 \mathrm{~Hz}$, all energy doses except $9 \mathrm{~J}$ caused a significant change in the fluorescence intensity of carboxyfluorescein. A $1.5 \mathrm{~J}$ dose caused the greatest reduction in stability. For $\mathrm{f}=2,000 \mathrm{~Hz}$, a $6 \mathrm{~J}$ dose had no significant effect on liposome stability, but stability was reduced at other doses $(\mathrm{p}<0.01)$. There were significant differences in the stability of PC liposomes between corresponding laser radiation energy doses at frequencies of $1,000 \mathrm{~Hz}$ and $2,000 \mathrm{~Hz}$, except for the $6 \mathrm{~J}$ dose $(\mathrm{p}<0.01)$ (Fig. 5).

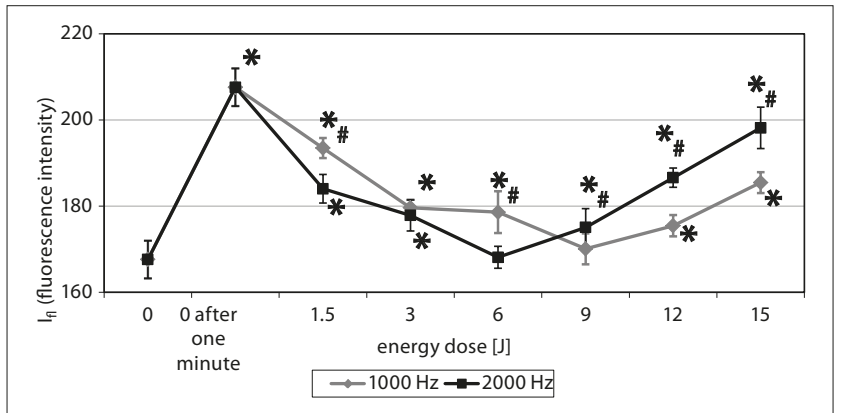

Figure 5. Fluorescence intensity of carboxyfluorescein in a phosphatidylcholine liposome suspension versus the dose of MLS laser radiation with frequency of $1,000 \mathrm{~Hz}$ and $2,000 \mathrm{~Hz}$.

* statistically significant difference, compared to a dose of $0 \mathrm{~J}$.

\# statistically significant difference between compared frequencies with the same energy dose.

Effects of MLS laser irradiation on stability of liposomes with lipid composition similar to human erythrocyte membranes. Irradiation at all energy levels and at both pulse frequencies reduced the stability of these liposomes significantly $(\mathrm{p}<0.001$ with respect to control values $(\mathrm{p}<0.01)$. For the $12 \mathrm{~J}$ dose there was no difference between the two frequencies ( $\mathrm{p}>0.05)$ (Fig. 6).

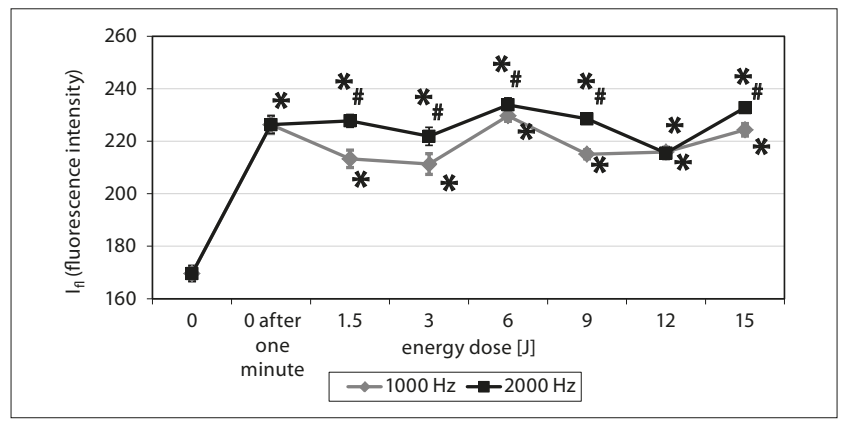

Figure 6. Fluorescence intensity of carboxyfluorescein in liposome suspension (with lipid composition similar to erythrocyte membranes) versus dose of MLS laser radiation with frequency of $1,000 \mathrm{~Hz}$ and $2,000 \mathrm{~Hz}$.

* statistically significant difference, compared to a dose of $0 \mathrm{~J}$.

\# statistically significant difference between compared frequencies with the same energy dose.

\section{DISCUSSION}

The literature suggests that the clinical effects of laser irradiation depend on: wavelength, power, energy dose, type of tissue exposed and energy application method (continuous or pulsed) $[10,11]$. Research shows that low-power laser 
irradiation (especially in the red and infrared ranges) accelerates cell proliferation, mainly through activating the mitochondrial respiratory chain and cell signalling cascades [12-15], and modulating cellular matrix metalloproteinase activities and gene expression [16]. Laser radiation is absorbed by cells due to the chromophores they contain. There are specific proteins called cytochromes, placed in the respiratory chain in mitochondria, that are responsible for the absorption. Other examples of chromophores are amino acids, nucleic acids, nicotinamide adenine dinucleotide (NAD) or haemoglobin. Laser radiation elicits both effects of reception and absorption on the cellular level. The effect of absorption evoked by induction of particles manifests itself by the increase of total cell energy, which includes the inner cell energy. The receptory effect is based on intensification of cellular metabolism. Absorption of laser radiation by cytochromes activates electron transport chain which induces the growth of ATP production and, as a result, speeds up metabolism. The effective energy increases at the expense of inner energy. The biostimulatory effect of laser radiation causes photoactivation of enzymes. Other exemplary effects on cellular level are: increase of DNA synthesis, increase of collagen synthesis, acceleration of membrane transport and improvement of membrane's permeability, modulation of system's immunological response and acceleration of oxyhaemoglobin dissociation [2-10].

Different research models, such as liposomes, are used to study changes in the structure and function of the plasma membrane. Research by the authors of the presented study has shown that low-energy laser irradiation at $1,000 \mathrm{~Hz}$ has a statistically significant effect on the fluidity of the inner monolayers of liposome membranes (Fig. 1a). The results show that the change depends on the frequency of laser radiation and the energy application rate, but not on the energy dose. Analysis of the obtained results shows a statistically significant effect of low-energy laser irradiation at $1,000 \mathrm{~Hz}$ and $2,000 \mathrm{~Hz}$ on the fluidity of liposome outer monolayers.

Low-energy laser irradiation caused an increase in liposome outer monolayer fluidity. This change was dependent on the frequency and energy dose of radiation. Radiation at $1,000 \mathrm{~Hz}$ also caused a significant increase in the 6-9 J range.

The results obtained in the current study demonstrate that laser radiation at lower frequency modifies the properties of the inner liposome monolayer. For radiation at $1,000 \mathrm{~Hz}$, this does not depend on the energy dose, but can be correlated with the rate of application of radiation energy. Radiation at $2,000 \mathrm{~Hz}$ (surface density $230 \mathrm{~mW} / \mathrm{cm}^{2}$ ) had no statistically significant effect on liposome structure. This could suggest that radiation at higher frequency and power is not sufficiently absorbed by the inner monolayer, or that the parameters used, including the energy application rate, are inadequate. In the presented study, laser irradiation at $1,000 \mathrm{~Hz}$ significantly reduced the fluidity of phosphatidylcholine liposome inner monolayers, while selected doses caused a statistically significant increase in fluidity of the outer monolayers. Radiation at $2000 \mathrm{~Hz}$ did not affect inner monolayer fluidity, but significantly increased outer monolayer fluidity. Therefore, treatments with $1,000 \mathrm{~Hz}$ and $2,000 \mathrm{~Hz}$ radiation affected the inner and outer monolayers of phosphatidylcholine liposomes selectively and in opposite ways, which could indicate the importance of differences in the absorption of laser radiation at the parameters used. The applied MLS at $1,000 \mathrm{~Hz}$ significantly reduced inner monolayer fluidity in liposomes with lipid composition similar to human red blood cell membranes. The observed effect could be related to the surface density of the applied radiation. As in the case of phosphatidylcholine liposomes, inner monolayer fluidity was reduced regardless of energy dose, even though the lipid composition of the liposome membrane was different.

On the other hand, radiation at $2,000 \mathrm{~Hz}$ caused a dosedependent effect, in contrast to the changes observed in phosphatidylcholine liposomes. A dose of $1.5 \mathrm{~J}$ at 2,000 Hz caused an effect similar to radiation at $1,000 \mathrm{~Hz}$. This could suggest that laser radiation at $1.5 \mathrm{~J}$ exerted a biostimulating effect, regardless of the energy application rate. The results showed that low-energy laser radiation at $1,000 \mathrm{~Hz}$ had no statistically significant effect on outer monolayer fluidity in liposomes with lipid composition similar to the human red blood cell membrane. However, there was a statistically significant increase in fluidity in the liposome outer layers for radiation at 2,000 Hz and energy does of $1.5 \mathrm{~J}$ and $3 \mathrm{~J}$. The fluidity changes showed no statistically significant dependence on the other energy doses. While analysing the results obtained in the current study, it was observed that MLS radiation at $1,000 \mathrm{~Hz}$ decreased the fluidity of the inner but not the outer monolayer in liposomes with lipid composition similar to the erythrocyte membranes. Radiation at this frequency had analogous effects on both types of liposomes. Radiation at 2,000 Hz, especially with an energy dose of $1.5 \mathrm{~J}$, increased the fluidity of the outer layer but decreased that of the inner monolayer. While it cannot be unambiguously determined which of these effects is beneficial, the study demonstrates that the biostimulating effect of laser radiation depends on the energy dose and frequency, and results in structural changes in liposome membranes. The presented findings could suggest that differences in the absorption of radiation are important and, among other factors, depend on the structure of the irradiated material.

Findings by other authors have revealed a statistically significant effect of laser radiation on human erythrocyte membrane fluidity $[18,19]$. Radiation at $810 \mathrm{~nm}$ with surface density $125 \mathrm{~mW} / \mathrm{cm}^{2}$ and energy doses of 3, 6, 9, 12, 15 and $20 \mathrm{~J}$ (respective surface energy densities 3.75, 7.5, 11.25, 15, 18.75 and $25 \mathrm{~J} / \mathrm{cm}^{2}$ ) caused statistically significant and dosedependent increases in fluidity in both the inner and the outer monolayers of erythrocyte membranes [18]. In the studies cited, 12-AS label was used (in addition to TMA-DPH and $\mathrm{DPH}$ ), which enabled variations in fluidity to be observed at the level of the 12th carbon atom in the fatty acid chains of the membrane phospholipids. Statistically significant stiffening of the red blood cell membrane in this area of the membrane was demonstrated for doses of 6,12 and $15 \mathrm{~J}$, while there was a statistically significant fluidization for $9 \mathrm{~J}$ and $20 \mathrm{~J}$. Kujawa et al. [18] applied continuous radiation; the MLS system emits synchronised continuous and pulsed radiation. Analysis of publications reveals that better results are obtained using pulsed laser radiation. Similar studies were carried out by Bryszewska and Leyko et al. [20], who subjected erythrocyte cell membranes to low power laser irradiation in the visible spectrum $(\lambda=670 \mathrm{~nm}, \mathrm{P}=7 \mathrm{~mW}, \mathrm{E}=5 \mathrm{~J})$. The results confirmed the effect of laser radiation on erythrocyte membrane microviscosity. For an energy dose of $5 \mathrm{~J}$, fluidity in the polar area of the membrane was significantly reduced. These authors [20] also demonstrated that changes in human erythrocyte membrane fluidity are caused by modifications 
within the lipid bilayer and in protein-lipid interactions. It should be noted that the fluorescence intensity in nonirradiated samples increased by a statistically significant amount after one minute (approximate time required for irradiation and start of measurement) and was greater than the fluorescence intensity in the irradiated samples.

Liposome stability was reduced more over time than under the influence of applied laser radiation. Because the difference was statistically significant for all doses (for both laser radiation frequencies), it can be concluded that laser radiation in itself inhibits the leakage of carboxyfluorescein from liposomes over time. The study revealed that low-energy laser irradiation has a significant effect on stability in liposomes with lipid composition similar to that of erythrocyte membranes. Radiation at all doses and both frequencies reduced liposome stability. Samples exposed to laser radiation had similar stability to controls after one minute, but the difference was statistically significant for doses of 1.5, 3, 9, $12 \mathrm{~J}$ (at 1,000 Hz) and 6, 12 and $15 \mathrm{~J}$ (at 2,000 Hz). In another experiment, erythrocyte membrane stability was tested by exposure to low-energy laser radiation at $\lambda=810 \mathrm{~nm}$ and powers of 200 $\mathrm{mW}$ and $400 \mathrm{~mW}$ (respective surface densities 250 and 500 $\mathrm{mW} / \mathrm{cm}^{2}$ ) at energy doses between $0-20 \mathrm{~J}$ (surface energy densities $3.75-25 \mathrm{~J} / \mathrm{cm}^{2}$ ) [21]. However, neither continuous nor fractionated radiation caused any stability changes in human erythrocyte membranes. A comparative analysis of stability in liposomes with lipid composition similar to that of erythrocyte membranes revealed statistically significant differences at laser radiation energy doses of 1.5, 3, 6, 9 and $15 \mathrm{~J}$ at $1,000 \mathrm{~Hz}$ and $2,000 \mathrm{~Hz}$. When the results obtained for phosphatidylcholine liposomes and liposomes with lipid composition similar to that of erythrocyte membranes were compared, statistically significant differences in stability were apparent after one minute. The phosphatidylcholine liposomes were more stable; the fluorescence intensity of the unexposed control after one minute was approximately $10 \%$ lower than that of liposomes with a composition similar to erythrocyte membranes (Ifl $=133.45 \%$ of control). It was also concluded that phosphatidylcholine liposomes are less susceptible to laser irradiation.

The liposome model only reflects the effect of radiation on lipid elements of cellular membrane. Wu et al. [22], in their research studied the influence of laser radiation (wavelength $660 \mathrm{~nm}$, power density was $15.17 \mathrm{~mW} / \mathrm{cm}^{2}$, cells irradiated for $264 \mathrm{~s}$ and $528 \mathrm{~s}$ to achieve energies of $4 \mathrm{~J} / \mathrm{cm}^{2}$ and $8 \mathrm{~J} / \mathrm{cm}^{2}$ ) on protein elements of cell membranes, and especially on toll-like receptors of Human Adipose-Derived Stem Cells (hADSCs). The results of that reseach proved that low-energy laser radiation inhibits inflammatory reaction induced by lipopolysaccharide ligand toll-like membrane receptors hADSCs, and that treatment with low-energy laser (LPLI treatment) can potentially be applied in anti-flammatory therapy followed by stem cell therapy.

Also, Giannelli et al. [23] studied the influence of laser radiation $(635 \mathrm{~nm}, 0.89 \mathrm{~W})$ on cells, particularly on proliferative mechanisms of mesenchymal stromal cells (MSCs). The researchers confirmed the increase of MSCs proliferation connected with activating of the Notch-I path and increased permeability of cell membrane for $\mathrm{K}^{+}$ions and T- and L-type calcium $\left(\mathrm{Ca}^{2+}\right)$ channels. According to the authors, laser stimulation may become a introductory stage for haematopoietic stem cell transplantation.

\section{CONCLUSIONS}

The presented study demonstrates that MLS laser radiation affects both the fluidity and the stability of liposomes in a manner dependent on the power and dose of radiation used. Since MLS M1 laser radiation, depending on the parameters used, affects fluidity and stability of liposomes with lipid content similar to erythrocyte membrane, it may also cause structural and functional changes in cell membranes. It is reasonable to assume that the selected doses of radiation energy with effects at the cellular level could have therapeutic efficacy. It is undoubtedly necessary to compare in vitro research results with the results of clinical studies using laser radiation with the same parameters. The practical aspect of the presented study important for clinicians is the identification of existing trends and dependencies between the effects of irradiation and the parameters of laser radiation used.

\section{Acknowledgement}

The authors express their thanks to the Medical University of Lodz for Grant No. 502-03/7-127-02/502-54-027.

\section{REFERENCES}

1. Chow RT, Johnson MI, Lopes-Martins RA, Bjordal JM. Efficacy of low-level laser therapy in the management of neck pain: a systematic review and meta-analysis of randomised placebo or active-treatment controlled trials. The Lancet. 2009; 374(9705): 1897 - 908.

2. Hegedüs B, Viharos L, Gervain M, Gálfi M. The Effect of Low-Level Laser in Knee Osteoarthritis: A Double-Blind, Randomized, PlaceboControlled Trial. Photomed Laser Surg. 2009; 27(4): 577-84.

3. Hashmi JT, Huang YY, Osmani BZ, Sharma SK, Naeser MA, Hamblin MR. Role of low-level laser therapy in neurorehabilitation. PM\&R. 2010; 2(12 Suppl 2): 292-305.

4. Ivandic BT, Ivandic T. Low-Level Laser Therapy Improves Visual Acuity in Adolescent and Adult Patients with Amblyopia. Photomed Laser Surg. 2012; 11: 167-71.

5. Mahram M, Rajabi M. Treatment of Lymphedema Praecox through Low Level Laser Therapy (LLLT). J Res Med Sci. 2011; 16(6): 848-51.

6. Mesquita-Ferrari RA, Ribeiro R, Souza NH, Silva CA, Martins MD, Bussadori SK, et al. No effect of low-level lasers on in vitro myoblast culture. Indian J Exp Biol. 2011; 49(6): 423-8.

7. Wu Q, Xuan W, Ando T, Xu T, Huang L, Huang YY, Dai T, Dhital S, et al. Low-level laser therapy for closed-head traumatic brain injury in mice: effect of different wavelengths. Lasers Surg Med. 2012; 24: 218-26.

8. Pagnutti S. Scientific Report MLS Therapy. Cutting Edge Laser Technology Press. Italy, 2004; 5-23.

9. Mognato M, Squizzato F, Facchin F, Zaghetto L, Corti L. Cell growth modulation of human cells irradiated in vitro with low-level laser therapy. Photomed Laser Surg. 2004; 22(6): 523-6.

10. Huang YY, Chen AC, Carroll JD, Hamblin MR. Biphasic dose response in low level light therapy. Dose Response. 2009; 7(4): 358-83.

11. Tafur J, Mills PJ. Low-intensity light therapy: exploring the role of redox mechanisms. Photomed Laser Surg. 2008; 26: 323-8.

12. Gao X, Xing D. Molecular mechanisms of cell proliferation induced by low power laser irradiation. J Biomed Sci. 2009; 16: 4-14.

13. Freitinger-Skalicka Z, Navratil L, Zolzer F, Hon Z. The Assessments of the Intracellular Antioxidant Protection of the Organism after LLLT Irradiation. AIP Conference Proceedings 2009; 1142(1): 87-91.

14. Dremza IK, Lapshina EA, Kujawa J, Zavodnik IB. Oxygen-related processes in red blood cells exposed to tert-butyl hydroperoxide. Redox Report. 2006; 11(4): 185-92.

15. Albertini R, Villaverde AB, Aimbire F, Salgado MAC, Bjordal JM, Alves LP, et al. Anti-inflammatory effects of low-level laser therapy (LLLT) with two different red wavelengths $(660 \mathrm{~nm}$ and $684 \mathrm{~nm}$ ) in carrageenan-induced rat paw edema. J Photochem Photobiol B. 2007; 89: $50-5$. 
16. Gavish L, Perez L, Gertz SD. Low-level laser irradiation modulates matrix metalloproteinase activity and gene expression in porcine aortic smooth muscle cells. Lasers Surg Med. 2006; 38: 779-86.

17. Chen ACH, Arany PR, Huang YY, Tomkinson EM, Saleem T, Yull FE, Blackwell TS, Hamblin MR. Low level laser therapy activates NF- $\kappa$ B via generation of reactive oxygen species in mouse embryonic fibroblasts. PLoS One. 2011; 6(7): e22453.

18. Kujawa J, Zavodnik L, Zavodnik I, Buko V, Lapshyna A, Bryszewska M. Effect of low-intensity $(3.75-25 \mathrm{~J} / \mathrm{cm} 2)$ near-infrared $(810 \mathrm{~nm})$ laser radiation on red blood cell ATPase activities and membrane structure. J Clin Laser Med Surg. 2004; 22(2): 111-7.

19. Kujawa J. Molekularne i błonowe mechanizmy biostymulacyjnych efektów promieniowania laserowego o długości fali $=810 \mathrm{~nm}$. (Molecular and membrane mechanisms of biostimulating effects of laser radiation with wavelength of $810 \mathrm{~nm}$ ) Habilitation dissertation in medical science in the field of medicine. Łodz. Medical University of Lodz Press, 2004.
20. Piasecka A, Leyko W, Krajewska E, Bryszewska M. Effect of combined treatment with perindoprilat and low-power red light laser irradiation on human erythrocyte membrane fluidity, membrane potential and acetylcholinesterase activity. Scand J Clin Lab Invest. 2000; 60(5): 395-402.

21. Kujawa J, Zavodnik L, Zavodnik I, Bryszewska M. Low-intensity near-infrared laser radiation-induced changes of acetylcholinesterase activity of human erythrocytes. J Clin Laser Med Surg. 2003; 21(6): 351-5.

22. Wu JY, Chen CH, Wang CZ, Ho ML, Yeh ML, Wang YH. Low-power laser irradiation suppresses inflammatory response of human adiposederived stem cells by modulating intracellular cyclic AMP level and NF- $\kappa$ B activity. PLoS One. 2013; 8(1): e54067.

23. Giannelli M, Chellini F, Sassoli C, Francini F, Pini A, Squecco R, Nosi D, Bani D, Zecchi-Orlandini S, Formigli L.Source. Photoactivation of bone marrow mesenchymal stromal cells with diode laser: effects and mechanisms of action. J Cell Physiol. 2013; 228(1): 172-81. 